Journal of Animal and Veterinary Advances 10 (11): 1368-1372, 2011

ISSN: $1680-5593$

(C) Medwell Journals, 2011

\title{
Study on the Risk Factors of Foot and Mouth Disease in Selected Districts of Afar Pastoral Area, Northeast Ethiopia
}

\author{
${ }^{1} \mathrm{~T}$. Shiferaw Jenbere, ${ }^{2}$ Manyahilishal Etana and ${ }^{3}$ Haileluel Negussie \\ ${ }^{1}$ National Veterinary Institute, P.O. Box 19, Debre Ziet, Ethiopia \\ ${ }^{2}$ Donkey Health and Welfare Project, School of Veterinary Medicine, \\ Addis Ababa University, P.O. Box 34, Debre Zeit, Ethiopia \\ ${ }^{3}$ School of Veterinary Medicine, Addis Ababa University, P.O. Box 34, Debre Zeit, Ethiopia
}

\begin{abstract}
The cross sectional study was conducted from October 2007 to April 2008 to determine seroprevalence and associated risk factors for seropositivity of FMD. Antibodies against non-structural protein of FMD virus (using 3ABC ELISA) were measured as indicator of exposure to the virus. An overall seroprevalence of 5.6\% (48.4\% at herd level) for FMD was found. Differences in geographical locations, age groups and herd sizes were risk factors found statistically $(p<0.05)$ associated with the occurrence of FMD. Any successful and cost effective intervention project to control FMD should therefore, consider these risk factors during project formulation.
\end{abstract}

Key words: Afar, FMD, pastoralists, $3 \mathrm{ABC}$ ELISA, risk factors, Ethiopia

\section{INTRODUCTION}

Foot and Mouth Disease (FMD) is a highly contagious and economically devastating disease of cloven-hoofed animals which can severely constrain international trade of animals and animal products. The disease has a high morbidity and low mortality with low occurrence in adult animals however, myocarditis may occur in young animals resulting to death. The recovered animals remain in poor physical condition over long periods of time leading to sustained economic losses for the livestock industry. Currently, it is present in two-thirds of the OIE member countries where it creates severe economic problems and provides a reservoir of disease ready to spread into disease free areas (Paarlberg et al., 2002; Clavijo et al., 2004). This study is therefore, designed to determine the seroprevalence and potential risk factors of FMD in selected districts of Afar pastoral area.

\section{MATERIALS AND METHODS}

Description of the study area: The Afar National Regional State (ANRS) is one of the major pastoral areas of Ethiopia situated in the northeastern part of the country between $39^{\circ} 34^{\prime}$ and $42^{\circ} 28^{\prime} \mathrm{E}$ longitude and $8^{\circ} 49^{\prime}$ and $14^{\circ} 30^{\prime} \mathrm{N}$ latitude. In most areas of the region, altitude ranges between $300-900 \mathrm{~m}$ above sea level. Specific areas such as Danakil depression and Afdera fall $126 \mathrm{~m}$ below sea level (CSA, 2004). The total amount of rain varies greatly from year to year and disruptions on the performance of any rainy season negatively impact on the availability of pasture and water causing drought and communities suffer considerable losses of livestock.

Study design and sampling method: A cross-sectional study design was used to determine the seroprevalence of FMD from September 2007 to April 2008 in selected Afar pastoral area of Ethiopia. In this study, based on geographical locations, accessibility, cattle resources and security, three zones in the region were selected from the existing five zones (Fig. 1). The four districts of Afar pastoral area where the study animals were selected were Chifra from zone one, Amibara and Gewane from zone three and Ewa from zone four. After having a complete list (sampling frame) of the Pastoral Associations (PAs) in each district, three PAs were selected randomly from each district. From the selected PAs, 10\% of the herds (a total of 64 herds) with 10-13 (20\%) animals per herd were randomly selected. Accordingly, a total of 12 PAs, 64 herds and 765 animals were included in this study. This number was distributed proportionally to the selected districts and PAs. A sample size of 765 was reached by assuming an expected prevalence of $21 \%$ reported by Rufael et al. (2008) in Borana pastoral area of Southern Ethiopia, 95\% confidence level and 5\% absolute precision. Win Episcope 2.0, an improved epidemiological

Corresponding Author: T. Shiferaw Jenbere, National Veterinary Institute, P.O. Box 19, Debre Ziet, Ethiopia 


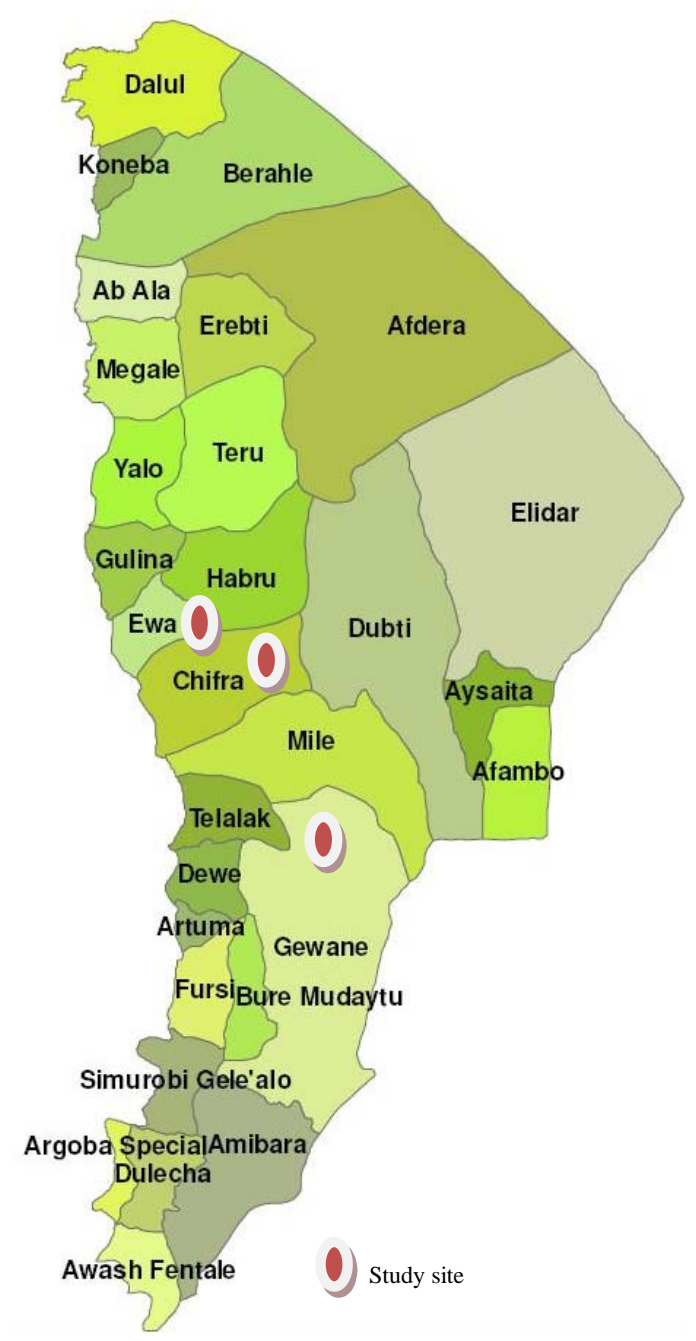

Fig. 1: Map of Afar region showing the five zones and the study districts

software for veterinary medicine developed for estimation of sample sizes in simple random sampling, yielded a sample size of 255 animals and according to Thrusfield (2005) for multistage cluster sampling, in the absence of between cluster variance, one can use the sample size estimated for simple random sampling provided that the estimated sample size should be inflated by between 2-4 folds to account for the potentially large variation that can occur between clusters (in this study by 3 times) and a sample size of 765 were achieved.

Clinical observations: All individual animals included in the study were clinically examined before sample collection paying particular attention to lesions of FMD. In addition, those animals belonged to the same herd but not included in the sample and diseased were also thoroughly examined after detailed interviewing and discussion with herd owners and clan leaders to evaluate the knowledge of the community about animal health problems.

Serum sample collection and analysis: Whole blood was collected from the jugular vein of each animal randomly selected from the herd and the blood was stored overnight at $+4^{\circ} \mathrm{C}$ (when conditions allowed) or at room temperature until the serum was separated (3-4 $\mathrm{h}$ on average). The serum was then transferred into a sterile cryotube bearing the name of the Pastoral Association (PA), age and sex of the animal and herd size. In the laboratory, the serum was stored at $-20^{\circ} \mathrm{C}$ while awaiting analysis. All sera were tested for the presence of antibodies produced against non-structural protein $3 \mathrm{ABC}$ of FMDV using a commercially available Chekit-FMD$3 \mathrm{ABC}-$ bo-ov ELISA kit. The assay was performed according to manufacturer's instructions and results were analyzed and interpreted using the formula:

$$
\text { OD value }(\%)=\left[\frac{\left(\mathrm{OD}_{\text {Sample }}-O D_{\text {Negative }}\right)}{\left(O D_{\text {Positive }}-O D_{\text {Negative }}\right)}\right] \times 100
$$

Samples were then categorized based on their Optical Density value $(\mathrm{OD} \%)$ as negative $(\mathrm{OD}<20 \%)$, ambiguous (OD between $20 \%-30 \%$ ) and positive ( $O D>30 \%$ ).

Data collection and analysis: Individual and herd level seroprevalence were calculated on the basis of $3 \mathrm{ABC}$ ELISA test results. Chi square $\left(\chi^{2}\right)$ were used to assess the existence of association between the assumed risk factor for the occurrence of FMD seropositivity. The degree of association between putative risk factor and seropositivity for those significantly associated factors were assessed using Odds Ratio (OR). All data related to serological investigation were imported to SPSS (2006) version 15.0 and STATA (2006) version 9.2 statistical software as appropriate. After checking for multicolinearity of variables by calculating the correlation coefficients, those factors not having strong linear relationship $(r<0.4)$ were used in the analysis. This enabled exclusion of confounding effects among the factors. Univariable logistic regression analysis was used to determine the association of each risk factor with seropositivity. A step-wise approach (forward selection and back ward elimination) using multivariable logistic regression was used to analyze those factors having putative effect on FMD occurrence based on a p-value $<0.05$ as a significance threshold for entries and removals. 


\section{RESULTS AND DISCUSSION}

Clinical observation during the study period showed that acute as well as chronic cases of FMD were not found in all the 64 herds examined in the study.

The seroprevalence of FMD in the four selected districts were $11.9 \%$ in Gewan, $5.2 \%$ in Chifra, $4.2 \%$ in Amibara and $2.9 \%$ in Ewa. The overall seroprevalence at individual and herds level were 5.6 and $48.4 \%$, respectively as shown in Table 1 .

Seroprevalence of FMD varied from district to district and this variation was statistically significant $\left(\chi^{2}=13.4\right.$, $\mathrm{df}=3, \mathrm{p}=0.004)$. The contribution of each district for the significance difference in seroprevalence was analyzed using logistic regression under univariable analysis of risk factors (Table 2).

The associations of individual categories of each risk factor with seropositivity of FMD were analyzed using univariable logistic regression and summary results of these analyses were shown in Table 1. The colinearity of the factors was checked before analysis and it was found to be $<0.4(\mathrm{r}<0.4)$ for all risk factors. This univariable analysis assumed all other factors were constant and one category was used as a reference. The odds of disease in Gewane were 3.1 times the odds of disease for the reference category (Amibara). Similarly the odds of disease in Ewa and Chifra were 0.7 and 1.3 times the odds of disease in Amibara, respectively. The district model was significant $(\mathrm{p}=0.007)$ and this was attributed mainly to Gewane.

In general as the herd size increased, the seroprevalence of FMD tended to increase and the herd size model was significant ( $p=0.019$ ). Similarly, as shown in Table 1, the seroprevalence of FMD increased with an increase in the age. The age group model was also significant $(p=0.007)$. However, the sex model was not significant $(\mathrm{p}=0.077)$ and thus the seroprevalence of FMD was not affected by sex.

Multivariable logistic regression analysis for assumed risk factors such as district (difference in ecology), herd size, age group and sex were conducted to see if there was any confounding effect between the risk factors. District, herd size and age group were found to be significantly associated with seropositivity of FMD as shown in Table 3.

Both during univariable and multivariable analysis, seropositivity was not significantly $(p>0.05)$ associated with sex. However, district, herd size and age group were significantly $(\mathrm{p}<0.05)$ associated with seropositivity. Sex was excluded from the final model and those variables that remained significant at both univariable and multivariable analysis were used to predict the occurrence of the FMD. As indicated by the correlation coefficient (Pseudo R) there was no multicolinearity among the various risk factors.

In this study a lower seroprevalence of $5.6 \%(48.4 \%$ at herd level) was obtained in contrast to Sahle (2004) and Rufael et al. (2008) who had reported higher seroprevalence of 26.5 and $21 \%$ (59\% at herd level), respectively. This variation in seroprevalence might be due to the difference in geographical area and/or the way sampling was conducted. The Afar, Somali and Borana pastoralists occupy a vast area of Ethiopia from Northeast to Southeast. In this region there was uncontrolled movement and frequent mixing of animals. The higher prevalence in Gewane was therefore, evidence of the high prevalence in Somali and Borana where Rufael et al. (2008) reported $21 \%$ prevalence. It worthy nothing that Gewane is part of Afar that shares most of the above

Table 1: Summary of herd and individual animal level seroprevalence of FMD in the selected districts and PAs

\begin{tabular}{|c|c|c|c|c|c|c|c|c|c|}
\hline \multirow[b]{2}{*}{ District } & \multirow[b]{2}{*}{ PA } & \multicolumn{4}{|c|}{ Herd level } & \multicolumn{4}{|c|}{ Individual animal level } \\
\hline & & Tested & Positive & Prevalence (\%) & $95 \% \mathrm{CI}$ & Tested & Positive & Prevalence (\%) & $95 \% \mathrm{CI}$ \\
\hline \multirow[t]{7}{*}{ Amibara } & Oudlis issi & 3 & 1 & 33.3 & & 33 & 2 & 6.10 & \\
\hline & Andido & 3 & 0 & 0.0 & & 38 & 0 & 0.00 & \\
\hline & Halydege & 4 & 3 & 75.0 & & 49 & 3 & 6.10 & \\
\hline & Total & 10 & 4 & 40.0 & $34.12-45.88$ & 120 & 5 & 4.25 & $2.82-5.65$ \\
\hline & Gelila dura & 3 & 1 & 33.3 & & 34 & 4 & 11.80 & \\
\hline & Bida & 3 & 2 & 66.7 & & 37 & 3 & 8.10 & \\
\hline & Gebey a bora & 5 & 5 & 100.0 & & 63 & 9 & 14.30 & \\
\hline \multirow[t]{4}{*}{ Gewane } & Total & 11 & 8 & 72.7 & $67.84-77.56$ & 134 & 16 & 11.90 & $9.61-14.2$ \\
\hline & Bilu & 4 & 1 & 25.0 & & 49 & 1 & 2.00 & \\
\hline & Meskid & 6 & 1 & 16.7 & & 66 & 1 & 1.50 & \\
\hline & Badule (1) & 7 & 4 & 57.1 & & 89 & 4 & 4.50 & \\
\hline \multirow[t]{4}{*}{ Ewa } & Total & 17 & 6 & 35.3 & $24.3-40.9$ & 204 & 6 & 2.90 & $1.71-4.09$ \\
\hline & Fecha & 7 & 3 & 42.9 & & 82 & 3 & 3.70 & \\
\hline & Jara & 9 & 4 & 44.4 & & 102 & 6 & 5.90 & \\
\hline & Duba & 10 & 6 & 60.0 & & 123 & 7 & 5.70 & \\
\hline Chifra & Total & 26 & 13 & 50.0 & $43.87-56.13$ & 307 & 16 & 5.20 & $3.63-6.77$ \\
\hline Overall total & & 64 & 31 & 48.4 & $42.28-54.52$ & 765 & 43 & 5.60 & $3.99-7.26$ \\
\hline
\end{tabular}


Table 2: Summary of the univariable analyses of the various risk factors with FMD seropositivity

\begin{tabular}{lclll}
\hline Risk factors & Coefficient & p value & Odds Ratio (OR) & $95 \%$ CI for OR \\
\hline District & - & 0.007 & - & - \\
Amibara* & - & - & - & - \\
Gewane & 1.137 & 0.031 & 3.119 & $1.106-8.793$ \\
Ewa & -0.361 & 0.558 & 0.697 & $0.208-2.335$ \\
Chifra & 0.235 & 0.654 & 1.265 & $0.453-3.532$ \\
Constant & -3.135 & 0.000 & 0.043 & - \\
Herd size & - & 0.019 & - & - \\
$<50^{*}$ & - & - & - & - \\
$50-100$ & 0.357 & 0.730 & 1.429 & $0.188-10.871$ \\
$>100$ & 1.281 & 0.224 & 3.600 & $0.457-28.333$ \\
Constant & -3.401 & 0.001 & 0.033 & - \\
Age group & & 0.007 & - & - \\
$<2^{*}$ & - & - & - & - \\
$2-4$ & 0.258 & 0.712 & 1.294 & $0.329-5.0910$ \\
$>4$ & 1.339 & 0.029 & 3.817 & $1.151-12.660$ \\
Constant & -3.746 & 0.000 & 0.024 & - \\
Sex & - & 0.077 & - & - \\
Male* & - & - & - & - \\
Female & 1.293 & 0.077 & 3.645 & $0.869-15.291$ \\
Constant & -3.998 & 0.000 & 0.018 & - \\
\hline
\end{tabular}

* Reference category

Table 3: Summary of multivariable logistic regression analysis for risk factors assumed to be associated with seropositivity of FMD

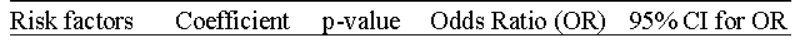

District

Amibara*

Gewane

$\quad 1.179$

Ewa

Chifra

Herd size

$>100^{*}$

$<50$

50-100

Age group

$<2 *$

2-4

$>4$

Sex

Female

Constant

$-1.376$

0.000

-

0.028

0.057

3.252

0.253

0.384

0.000

$-$

$-1.208$

$-2.038$

-

$-$

0.284

1.484

-

$-4.569$

0.260

0.000

0.003

0.687

0.017

0.054

0.054

0.002

$-$

0.299

0.130

-

1.329

4.412

$-$

4.201

0.010

Reference category. Number of obs. $=765 ;$ LR $\chi^{2}(4)=28.02$; Prob. $>\chi^{2}=0.0000 ;$ Pseudo $\mathrm{R}^{2}=0.0846$

condition with Somali region and their proximity could have contributed to variation in seroprevalence recorded in this study. Moreover if sampling was based outbreaks, this could also contribute to the higher prevalence recorded in the above two reports.

Clinical cases of FMD were not seen during the study period in the selected districts and all animals that reacted positively to $3 \mathrm{ABC}$ ELISA were apparently health. These animals could be persistently infected or carriers of FMDV as described by Van Bekkum et al. (1959), Malirat et al. (1994), Alexandersen et al. (2002) and Vosloo et al. (2002). Since the phenomenon of carrier state in cattle is a well-established fact, these animals could pose risk to susceptible animals and play a role in the maintenance of the agent as well as epidemiology of the disease in the Afar pastoral area.
At district level seroprevalence was significantly higher in Gewane (11.9\%) as compared to Amibara, Ewa and Chifra. Conflicts with the neighboring Issa clan were a major problem for Afar pastoralists and this was very serious in Gewane compared to the other three districts. In turn issa was frequently battling Borana pastoralists. These conflicts in pastoral areas result in losses of human lives and theft of livestock particularly cattle and camels. Consequently, there were constant and uncontrolled movements of animals among these pastoral areas in all directions. These uncontrolled movements might explain the high prevalence of FMD recorded in Gewane. The role of wild life in the epidemiology of FMD has been reported by various researchers (Hedger and Condy, 1985; Thomson et al., 1992; Alexandersen et al., 2002). In this study pastoralists also mentioned presence of wart hog as a source of infection for cattle herds and exceptionally high population of wart hog were noticed in Gewane district that might again contributed to the higher prevalence of FMD in Gewane.

In agreement with Rufael et al. (2008), the occurrence of FMD was increasingly associated with increasing herd sizes as shown both by the results of univariable and multivariable logistic regression analyses. This could be explained by the contagious nature of the disease and its mode of transmission which could be enhanced by crowding and increased frequency of contacts as herd size increases (Donaldson et al., 2001; Gloster, 2004). In addition, the Afar pastoralists are known by having large herd sizes and from these herds animal takeoff were very insignificant and hence there was a high chance of individual animals to stay in the herd for life-long. Therefore, there was a high chance for the virus to circulate in the herd if once entered into a large sized herd.

\section{CONCLUSION}

In this study the seroprevalence investigation of FMD indicated that intrinsic as well as extrinsic epidemiological risk factors such as herd size, difference in geographical location (district) and age of the animal were associated with seropositivity. Therefore, any successful and cost effective intervention project designed to control FMD at large scale should consider those risk factors associated with seropositivity during project formulation. Afar pastoral area is among the parts of the country frequently strike by recurrent drought that result in critical shortage of pasture. These conditions are aggravated by the current fast spreading trends of P.juliflora. This plant has invaded most of the fertile grazing lands and if this continues, it seriously jeopardizes pastoralists existence in the short foreseeable 
future. Hence, in order to secure the existing grazing land for pastoralists, the regional government should take actions against further spreading of $P$. juliflora and livestock development projects executed in pastoral areas should also center pastoralists interest and their knowledge in order to ensure sustainability.

\section{REFERENCES}

Alexandersen, S., Z. Zhang and A.I. Donaldson, 2002. Aspects of the persistence of foot-and-mouth disease virus in animals-the carrier problem. Microbes Infect., 4: 1099-1110.

CSA, 2004. Livestock sample survey. Central Statistical Agency of Ethiopia, Agriculture and Natural Resources Statistics Department, Addis Ababa, Ethiopia.

Clavijo, A., P. Wright and P. Kitching, 2004. Developments in diagnostic techniques for differentiating infection from vaccination in footand-mouth disease. Vet. J., 167: 9-22.

Donaldson, A.I., S. Alexandersen, J.H. Sorensen and T. Mikkelsen, 2001. Relative risks of the uncontrollable (airborne) spread of FMD by different species. Vet. Rec., 148: 602-604.

Gloster, J., 2004. New directions: Airborne transmission of foot-and-mouth disease virus. Atmos. Environ., 38: 503-505.

Hedger, R.S. and J.B. Condy, 1985. Transmission of foot-and-mouth disease from African buffalo virus carriers to bovines. Vet. Rec., 117: 205-208.
Malirat, V., P.A. de Mello, B. Tiraboschi, E. Beck, I. Gomes and I.E. Bergmann, 1994. Genetic variation of foot-and-mouth disease virus during persistent infection in cattle. Virus Res., 34: 31-48.

Paarlberg, P.L., J.G. Lee and A.H. Seitzinger, 2002. Potential revenue impact of an outbreak of foot-andmouth disease in the United States. J. Am. Vet. Med. Asso., 220: 988-992.

Rufael, T., A. Catley, A. Bogale, M. Sahle and Y. Shiferaw, 2008. Foot and mouth disease in the Borana pastoral system, southern Ethiopia and implications for livelihoods and international trade. Trop. Anim. Health Prod., 40: 29-38.

SPSS, 2006. SPSS 15.0 for Windows Evaluation Version. Version 15.0.0, SPSS Inc., USA.

STATA, 2006. Intercooled Stata 9.2 for windows. STATA, USA.

Thomson, G.R., W. Vosloo, J.J. Esterhuysen and R.G. Bengis, 1992. Maintenance of foot and mouth disease viruses in buffalo (Syncerus caffer Sparrman, 1779) in Southern Africa. Rev. Sci. Tech., 11: $1097-1107$.

Thrusfield, M., 2005. Veterinary Epidemiology. 3rd Edn., Blackwell Publishing, Incorporated, Ames, Iowa.

Van Bekkum, J., S. Frenkel, H.J. Frederiks and S. Frenkel, 1959. Observations on the carrier state of cattle exposed to foot-and-mouth disease virus. Bull. Int. Epizoot., 51: 917-922.

Vosloo, W., A.D. Bastos, O. Sangare, S.K. Hargreaves and G.R. Thomson, 2002. Review of the status and control of foot and mouth disease in sub-Saharan Africa. Rev. Sci. Tech., 21: 437-449. 